\title{
Primary health care in Africa: do family physicians fit in?
}

Jan De Maeseneer and Maaike Flinkenflögel

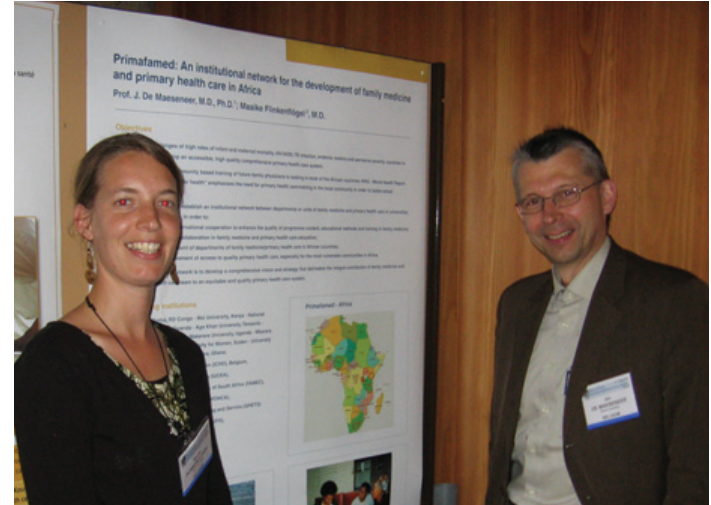

\section{INTRODUCTION}

Family medicine or 'general practice' is a very recent discipline in medicine, if you look at it in terms of academic recognition. In 1963 the University of Edinburgh appointed Richard Scott as the first professor of family medicine in the world. ${ }^{1}$ Family medicine was a concept, mainly developed in western countries, starting with postgraduate training in the 1960s. In the 1970s and 1980s, the discipline developed a specific approach to patients and health problems: a biopsychosocial frame of reference, looking at context, utilising doctor-patient communication as an important tool, taking advantage of medical decision making, and comprehensively integrating the care of patients with multimorbidity, functioning in a multidisciplinary primary healthcare team. Although the ancestors of

J De Maeseneer, MD, PhD; M Flinkenflögel, $M D$, Department of Family Medicine and Primary Health Care Ghent University, Belgium. This text is based on the Richard Scott Lecture delivered at the University of Edinburgh on 25 May 2009.

Address for correspondence

Professor Jan De Maeseneer, Department of Family Medicine and Primary Health Care, Ghent University, UZ-1K3, De Pintelaan 185, Ghent, B-9000, Belgium. E-mail: maaike.flinkenflogel@ugent.be

Submitted: 3 April 2009; Editor's response: 23 June 2009; final acceptance: 8 September 2009.

(OBritish Journal of General Practice 2010; 60: 286-292.

DOI: 10.3399/bjgp10X483977 family medicine were medical practitioners who were highly motivated to contribute to the welfare of the poor through a community-oriented approach, the main focus in the early years of family medicine was on the relationship of the physician with the individual patient and his/her family. It was mainly public health programmes that looked at the broader societal context and tried to act at that level.

The World Health Organization (WHO) Alma-Ata Declaration on primary health care which stated 'health for all by the year 2000' did not mention the discipline of family medicine. ${ }^{2}$ In the last 30 years, all over the world, primary health care has developed and, increasingly, the awareness has grown that there is need for a specific medical clinical discipline in primary health care: the GP/family physician. In Africa, the term 'family physician' is used, as a GP in Africa is most of the time a 'medical officer' working in private or public practice without any further training after the undergraduate medical curriculum. The question is, what should be the profile of a family physician in Africa, in order to be responsive to the needs of the local population? This lecture explores this further and will look at the following three questions:

- What can be the contribution of family medicine, in the framework of primary health care, to address the social determinants of health?

- What choices in health care are needed to make change happen?

- What can be the place of family medicine in the primary healthcare system and primary care teams in Africa?

\section{HOW CAN FAMILY MEDICINE CONTRIBUTE TO ADDRESS THE SOCIAL DETERMINANTS OF HEALTH?}

The Commission on Social Determinants of Health of WHO launched the report Closing the Gap in a Generation: Health Equity Through Action on the Social Determinants of Health in November $2008 .^{3}$ The executive summary of the report states clearly in the chapter 'Universal Health Care':

'Healthcare systems have better health outcomes when built on primary health care 
(PHC) - that is, both the PHC-model that emphasises locally appropriate action across the range of social determinants, where prevention and promotion are in balance with investment in curative interventions, and an emphasis on the primary level of care with adequate referral to higher levels of care."3

\section{How could this work?}

Primary healthcare teams not only address the needs of the individuals, but are also looking at the community, especially when addressing social determinants of health. Therefore, there is an increasing interest in integration of primary health care with public health approaches. ${ }^{4}$ Communityoriented primary care (COPC) consists of a systematic assessment of healthcare needs in the practice population, identification of community health problems, implementation of systematic interventions, involving the target population (for example, modification of practice procedures, change of lifestyle, and improvement of living conditions), and monitoring of the impact of the changes to ensure that health services are improved and congruent with community needs. ${ }^{5}$ COPC teams design specific interventions to address priority health problems. A team consisting of primary healthcare workers and community members assesses resources and develops strategic plans to deal with the problems that have been identified. COPC integrates individual and population-based care, blending the clinical skills of the practitioner with epidemiology, preventive medicine, and health promotion. By doing so, it tries to minimise the separation between public health and individual health care.

Our hypothesis is that primary health care can be a strategy for promoting health equity and intersectoral action. The first prerequisite is a high level of accessibility of the primary healthcare team. The second is that the team should deliver highquality care. Moreover, the team should interact with different networks (such as, education, work, economy, and housing) that are related to important sectors. Apart from an approach to individuals and families, the primary healthcare team should also address the community, utilising the COPC strategy. COPC, the direct action of the primary healthcare team, and intersectoral networking will enhance the social cohesion in the community. The actions of the primary healthcare team, curative and preventive, and the increased social cohesion in the community will lead to empowerment of the people. This empowerment is situated at different levels: physical, psychological, social, and cultural. The empowerment of the population will decrease the

\section{How this fits in}

Both the World Health Report 2008: Primary Health Care: Now More Than Ever and the report of the Commission on Social Determinants of Health of the

WHO: Closing the Gap in a Generation have challenged the priorities in primary care, including the family physicians/GPs, to reflect on the social accountability of their professional contributions. In this lecture we address this challenge from three perspectives; addressing the social determinants, the important choices in health care (horizontal versus vertical approach) and the implementation in the African context. Well-trained family physicians/GPs, operating in a communityoriented primary healthcare team, can contribute - also in Africa - to the achievement of the fundamental right of every citizen to have access to personoriented quality primary health care.

vulnerability to factors that may contribute to health inequity. Moreover, as the COPC action will address the living conditions of the local population, the exposure of the people to factors that may be a threat to their health will diminish and the differential vulnerability will decrease. Finally, a better education, better working conditions and decreased unemployment, better housing conditions, and access to safe food and water, will improve the structural determinants that influence the social stratification.

Is the hypothesis that primary health care, through its contribution to social cohesion and empowerment, addresses the social determinants of health, documented by research findings?

In an excellent article, Barbara Starfield et al gave an overview of the contributions of primary care to health systems and health. ${ }^{6}$ Some studies looked at the impact of primary care on reductions in disparities in health: studies of physician supply, studies of the association with a primary care physician, and studies of the receipt of services that fulfilled the criteria for primary care delivery. ${ }^{6}$ Higher ratios of primary care physicians to population are associated with relatively greater effects on various aspects of health in more socially-deprived areas (as measured by high levels of income inequalities). Areas in the US with abundant primary care resources and high income inequality have a $17 \%$ lower post-neonatal mortality rate (compared with the population means); whereas the post-neonatal mortality rate in areas of high income inequality and few primary care resources has been shown to be $7 \%$ higher than the population mean. ${ }^{7}$

The fact that primary care, particularly family medicine, was found to be associated with better health outcome suggests that improving the ratio of primary care (especially family medicine physicians) to population could improve health outcomes, even in states with serious health inequalities. ${ }^{8}$ Eleven years of state-level data found the supply of primary 
care physicians to be significantly related to lower all-cause-mortality rates in both African-American and white populations, after controlling for income inequality and socioeconomic characteristics (metropolitan area, percentage of unemployed, and educational levels). In these state-level analyses, the supply of primary care physicians had a greater positive impact on mortality among African-Americans than among whites. The association between a greater supply of primary care physicians and lower total mortality was found to be four times greater in the African-American population than in the white majority population, indicating a reduction in racial disparities in mortality in the US states. ${ }^{8}$

The equity-related effect of having a good primary care source was also found in a study that examined the degree of primary care-oriented services that people received. Good primary care experiences were associated with reductions in the adverse effects of income inequality on health, with fewer differences in self-rated health between higher and lower income-inequality areas where primary care experiences were stronger. ${ }^{9}$ Another study showed that among white and African-American populations in both urban and rural areas in the US, the rates of low birth weight were lower, in absolute numbers and ratios of rates, where the source of care was a community health centre. ${ }^{10} \mathrm{~A}$ study comparing the situation of diabetes-related lower-extremity amputation in the UK and the US concluded that in the US the black population had rates that were two to three times higher than in the white population, whereas in the UK, the rates were lower in black men than in the white population. The findings persisted even after controlling for socioeconomic differences, thus confirming other findings that a health system oriented towards primary care services (such as in the $U K$ ) reduced the disparities in health care that are so prominent in the US. ${ }^{11}$

Primary care programmes, aimed at improving health in deprived populations in less developed countries, succeeded in narrowing the gaps in health between socially-deprived and more sociallyadvantaged populations. A matched case-control study in Mexico found that some aspects of primary care delivery had an important independent effect on reducing the odds of children dying in sociallydeprived areas. These processes included adequate referral mechanisms, continuity of care (being seen by the same provider at each visit), and being attended in a public facility designed to provide primary care. ${ }^{12}$

A study in Bolivia found that a community-based approach to planning primary healthcare services in socially-deprived areas lowered the mortality of children under the age of 5 years, compared with adjacent similar areas of the country as a whole. ${ }^{13}$ In Kerala (India), $74 \%$ of the population lives in a village with a primary healthcare centre. Their infant mortality rate is 16 per 1000 live births. By contrast, in Uttar Pradesh State, only $4 \%$ of the population has access to primary health care, and the infant mortality rate is 87 per 1000 births. ${ }^{14}$

Studies in other developing countries showed the considerable potential of primary health care to reduce the large disparities associated with socioeconomic deprivation. In seven African countries, the wealthiest $20 \%$ of the population receives well over three times as much financial benefit from overall government spending as does the poorest $20 \%$ of the population $(40 \%$ versus $12 \%)$. For primary care services, the ratio of rich to poor in the distribution of government expenditures was notably lower (23\% to the top group versus $15 \%$ to the lowest group), leading one international expert to conclude that 'from an equity perspective, the move towards primary care represents a clear step in the right direction'. ${ }^{15}$ An analysis of preventable deaths in children concluded that in the 42 countries accounting for $90 \%$ of child deaths worldwide, $63 \%$ of deaths could have been prevented by the full implementation of primary care. The primary care interventions included integrated care addressing the very common problems of diarrhoea, pneumonia, measles, malaria, HIV/AIDS, preterm delivery, neonatal tetanus, and neonatal sepsis. ${ }^{16}$

Starfield et al find a rationale for the benefits of primary care for health in:

- greater access to needed services;

- better quality of care;

- a greater focus on prevention;

- early management of health problems;

- the cumulative effect of the main primary care delivery characteristics; and

- the role of primary care in reducing unnecessary and potentially harmful specialist care.

The 'evidence' for this impact can be found in the original article by Starfield et al. ${ }^{17}$ Within the scope of this lecture, we limit ourselves to the first point: primary care increases access to health services for relatively deprived population groups. Primary care is the point of first contact with health services, and facilitates access to the rest of the health system. In the US, socially-deprived population subgroups are more likely to lack a regular source of care than more advantaged people. ${ }^{18,19}$

At present in many countries, health care is uncoordinated access to hospital, and specialist care is unrestricted for those who can afford it. Yet, direct 
specialist care often leads to a very costly cascade of diagnostic and therapeutic interventions, with even some potential for iatrogenic peril. The primary healthcare team is the point of access to medical care for the whole community and functions as 'navigator' through secondary and tertiary care and other sectors. The vast majority (over 90\%) of presented problems - all the 'common' illnesses are managed at the inexpensive primary care level. ${ }^{20}$ Difficult or uncommon problems are referred by the navigator primary healthcare team, which leads the patients through the complicated medical maze of specialists and procedures, thus making sure that the patients receive the most appropriate care, and avoiding unnecessary costs due to a mismatch of specialist and medical problems. This leads to better health outcomes, and at the same time makes health care much more cost-effective. The expensive, and often inadequate, use of specialist care will diminish, and the use of financial resources will be optimised. Money saved by avoiding unnecessary healthcare expenditures becomes available for further development and extension of and improved and increased access to primary health care, and for making secondary care affordable for those who need it. Maximal access to primary health care with sufficient referral opportunity will decrease health inequality and the differences in vulnerability.

Research has shown that in industrialised countries, health expenditure per capita is on average less in countries with a strong primary care orientation, including the navigator function. ${ }^{21}$ For developing countries, research data are lacking, but there would be no reason why results would be different.

To make this happen there is a need for a comprehensive medical clinical discipline that puts into practice the shift from 'primary medical care' to 'primary health care'. Table 1 illustrates this shift.

\section{CHOICES IN HEALTH CARE: HORIZONTAL VERSUS VERTICAL APPROACHES}

In most developing countries, the majority of resources go to secondary and tertiary care hospitals, looking after a small part of the population. As in western countries, the attractiveness and the 'power' of hospitals in the healthcare system are quite strong. A hospital is more 'visible'. Primary health care is much more dispersed in the community, under the form of clinics, community health centres, and district health hospitals. In the last 20 years, another 'antagonism' has become increasingly important: the antagonism between horizontal (person- and community-oriented care) and vertical (disease-oriented) care. Shortly after the
Table 1. From primary medical care to primary health care, adapted from Vuori (1985). ${ }^{22}$

\begin{tabular}{|c|c|c|}
\hline Conventional & & New \\
\hline $\begin{array}{l}\text { Illness } \\
\text { Cure }\end{array}$ & Focus & $\begin{array}{l}\text { Health Prevention, } \\
\text { care and cure }\end{array}$ \\
\hline $\begin{array}{l}\text { Treatment } \\
\text { Episodic problems } \\
\text { Specific problems }\end{array}$ & Content & $\begin{array}{l}\text { Health promotion } \\
\text { Continuous care } \\
\text { Comprehensive care }\end{array}$ \\
\hline $\begin{array}{l}\text { Specialist physicians } \\
\text { Single-handed practice }\end{array}$ & Organisation & $\begin{array}{c}\text { Family physicians/GPs } \\
\text { Other personnel groups } \\
\text { Team }\end{array}$ \\
\hline $\begin{array}{l}\text { Health sector alone } \\
\text { Professional dominance } \\
\text { Passive reception }\end{array}$ & Responsibility & $\begin{array}{c}\text { Intersectoral collaboration } \\
\text { Community participation } \\
\text { Self-responsibility }\end{array}$ \\
\hline
\end{tabular}

Alma Ata Declaration, where the importance of comprehensive primary health care was pointed out by the $\mathrm{WHO},{ }^{2}$ the concept of selective primary health care underpinned the vertical 'disease-oriented' programmes. The AIDS epidemic in the 1980s gave a strong impetus to the development of vertical programmes. Organisations such as The World Bank, the International Monetary Fund (IMF), the Global Fund, Bill and Melinda Gates Foundation, and US-Aid, have concentrated on vertical programmes. Although enormous amounts of money are invested in those vertical programmes, the overall performance of disease control programmes is poor. $^{23}$ For tuberculosis, HIV, and malaria, the Millennium Development Goals will not be met in Latin America, Sub-Saharan Africa, or South and South-East Asia. An overview of the literature on vertical versus horizontal programmes found very few studies providing empirical evidence in this area, and the overall quality of the studies was less than desirable. The authors conclude that vertical and horizontal approaches do not have to be seen as mutually exclusive but rather as complementary strategies, thus pointing to the need to discard the dichotomy of the one versus the other:

'Given the capacity constraints of existing services, expansion of access to priority interventions which can feasibly be delivered independently of the health service infrastructure, may need to rely on verticallydelivered programmes in the first instance. ${ }^{24}$

This contradicts other literature that demonstrates clearly that there is a need to integrate programmes into local health facilities to achieve reasonable prospects for successful disease control. ${ }^{25-27}$ These authors point to the merit of integrating curative and preventive care. Examples include the potential for detecting a patient with tuberculosis among those with cough, or suggesting vaccination to a patient or 
to a population with whom the practitioner (for example, a family physician or nurse clinician) has established trust. Ooms et al even suggest a diagonal approach to decrease the polarisation in the discussion between horizontal versus vertical care programmes. ${ }^{28}$ The authors suggest that the the Global Fund should gradually and carefully be transformed into a 'diagonal' and ultimately perhaps 'horizontal' financing approach.

The problem with vertical programmes is that they address only a fraction of the demand or need for health care. Patients are likely to demand a range of treatments, spanning curative care, relief from suffering, reassurance, prevention, and advice on use of health services - not just a control of one single cause of ill-health. In contrast, vertical programmes focus on restricted objectives, largely ignoring the patient's demand for access to wider health care. This dialogue between 'programme', professional, and patient is limited to matters of education and information - one-way communication - to promote the campaign objectives. ${ }^{29} \mathrm{~A}$ report prepared for the Swiss Agency for Development and Cooperation identifies other disadvantages of vertical programmes: they create duplication (each single disease control programme requires its own bureaucracy), lead to inefficient facility utilisation by recipients, may lead to gaps in care, are incompatible with decent healthcare delivery and, where funded externally, undermine government capacity by reducing the responsibility of the state to improve health care in its own services. ${ }^{30}$

Recently, a new phenomenon is influencing the developments in a negative way: vertical diseaseoriented programmes, funded by international donors, 'extract' the skilled local health personnel out of the local primary healthcare system in order to employ them, in much better financial conditions, in vertical programmes. This type of internal 'braindrain' has devastating consequences.

To deal with these problems, a 'code of best practice for disease control programmes to avoid damaging healthcare services in developing countries' has been established:

- disease control activities should generally be integrated, with the exception of certain welldefined situations. They should be integrated in health centres, which offer patient-centred care;

- disease control programmes should be integrated in not-for-profit health facilities;

- disease control programmes should plan to avoid conflict with healthcare delivery; and

- the administration of disease control programmes should be designed and operated to strengthen health systems. ${ }^{29}$
In March 2008 the '15by2015' campaign was started. ${ }^{31,32}$ The World Organization of Family Doctors (WONCA) in collaboration with Global Health through Education, Training and Service (GHETS), the Network Towards Unity for Health, and the European Forum for Primary Care (EFPC), called upon the new international health partnership and upon funding organisations, such as the Global Fund, the World Bank, the Bill and Melinda Gates Foundation, and the World Health Organization, to assign primary health care a pivotal role by investing, by $2015,15 \%$ of the budget of vertical disease-oriented programmes in strengthening well-coordinated, integrated local healthcare systems and asking that this percentage would increase over time.

How could '15by2015' work? Take the example of Mozambique. In 2005, the total health expenditure in the country was $\$ 356$ million. Foreign assistance accounted for $\$ 243$ million, from which $\$ 130$ million was channelled through disease-specific vertical funds managed directly by donors. ${ }^{33}$ The ' 15 by 2015 ' campaign proposes that $15 \%$ of the vertical funds from donor organisations (in this example, $\$ 19.5$ million) should be diverted into the government's common health fund and be earmarked for strengthening primary health care through improvement of infrastructure, health education, and investment in human resources. This amount of money could support 65 health centres for a year. These centres could be staffed by primary healthcare teams including family physicians, midlevel care workers, primary care nurses, pharmacists, and health promoters.

If one primary healthcare centre covers a population of 20000 people, then 65 health centres would give 1.3 million people access to improved primary health care. Part of the '15by2015' fund could be allocated to support the training and upgrading of skills. It could also be used to provide better pay for health personnel to encourage them to stay in areas where they are needed, and to pay for community health workers, mid-level care workers, and 'African family physicians' who are a fledgling but emerging force. ${ }^{34,35}$ The Ministry of Health should monitor the accessibility and quality of this care in a transparent way to ensure that the ' 15 by2015' fund is used most effectively to improve community health.

This comprehensive, universal approach with primary health care as the hub of coordination and networking within the community, is exactly what the 2008 World Health Report Primary Health Care: Now More Than Ever advocates. ${ }^{36}$ In the chapter 'Primary Care: Putting People First', there is a clear focus on person-centred care, comprehensive and integrated responses, continuity of care, and a regular and 
trusted provider as entry. This is exactly where these skills and competences of a family physician, operating in a primary healthcare team, are required.

\section{HOW COULD THIS WORK IN AFRICA: THE 'AFRICAN FAMILY PHYSICIAN'?}

Mash et al explored the key principles of family medicine in Sub-Saharan Africa, using an international Delphi-consensus process. ${ }^{37}$ The study revealed that core values and characteristics such as an holistic, longitudinal, comprehensive, and familyorientated care and community orientation, were recognised as relevant, with differences from more developed settings in terms of emphasis. Several key organisational principles, such as home visiting and definition of the practice population, were seen differently from family medicine in developed countries. Principles related to the scope of practice showed the greatest difference, with the need for family physicians to perform major surgery in the district hospital, and to act as consultant and teacher to the first-contact primary healthcare team being raised. This first study invites further reflection on the specificities of the role of family physicians in the African context. However, it makes clear that there is a specific role for a medical clinical discipline in the primary healthcare team.

Interestingly, community-oriented primary health care originated in South Africa in the 1940s. In the 1990s, community-oriented primary health care played an inspirational role in the national health policy formulation..$^{38}$ South Africa is the first African country where family medicine became part of the healthcare system, and family physicians are integrated in primary healthcare teams in the community. Hugo et al describe in Doctors for Tomorrow: Family Medicine in South Africa, that from 2008 every South African family physician has to be trained in a public-sector district hospital; this is the lowest level of care where doctors are working in primary health care. ${ }^{39}$ The eight departments of family medicine are working together through the Family Medicine Education Consortium (FaMEC) and the South African Academy of Family Practice. From South Africa, family medicine training is expanding all over the continent. More and more universities in other Sub-Saharan African countries are starting to train doctors in primary health care - the new African family physicians.

The Primafamed Edulink EU-ACP project is working together with 10 universities in eight SubSaharan African countries where the postgraduate family medicine training for local doctors is developing within the faculty of medicine. ${ }^{35}$ The trainees are working in training sites, mainly in district hospitals, under supervision of family physicians, with input of other specialists when needed. In most countries there is an ongoing discussion with the ministry of health to integrate family medicine in the existing health systems. In several countries such as South Africa, Kenya, and Rwanda, family medicine has been accepted as a specialisation, paying family physicians salaries that are equal to those of other trained colleagues such as surgeons and paediatricians working in public health care. In each country, the training is adjusted to the needs of the local community, but the holistic approach, delivering comprehensive quality care, and the role of the family physician in the primary healthcare team are retained. South Africa is often seen as the role model in training African family physicians, and the experience of the South African departments of family medicine is used regularly, South-South cooperation, networking, and twinning of universities to share ideas, material, and knowledge is of utmost importance in the expansion of African family medicine and integration of the new concept in the healthcare systems of each country.

\section{CONCLUSION}

When we look back at the history of medicine teaching at the University of Edinburgh, it is obvious that already in the 18th century, there was a link between teaching students and the emphasis on those most in need: the poor who were not able to afford medical attention. Role models such as Andrew Duncan, demonstrated what the social accountability of a medical doctor should be and how training should be relevant for the needs of the global population. This is exactly what forms the focus of family medicine training in the framework of the primary healthcare teams in Africa: the focus on the contribution primary health care makes to improvement of the welfare of the poor by addressing the social determinants of health in the community. Linking education to practice, has been, and is still, a key feature of a socially accountable medical faculty. Also in Africa, which suffers more than any continent from a focus on specialty care in central hospitals in big cities, we have to bring the students to those areas and people that are most in need. So, the heritage of Duncan, Mackenzie, Scott, Kark, and so many others still inspires a worldwide commitment to achieve the fundamental right of every citizen: to have access to person-oriented, comprehensive, and community-embedded quality primary health care.

\section{Competing interests}

The authors have stated that there are none.

Discuss this article

Contribute and read comments about this article on the Discussion Forum: http://www.rcgp.org.uk/bjgp-discuss 


\section{REFERENCES}

1. Thomson MD. General Practice and the Edinburgh Medical School: 200 years of teaching, care and research. JR Coll Gen Pract 1984; 34(258): 9-12.

2. World Health Organization. Declaration of Alma-Ata. International Conference on Primary Health Care, Alma-Ata, USSR, 6-12 September 1978 .

http://www.who.int/hpr/NPH/docs/declaration_almaata.pdf (accessed 9 Mar 2010).

3. Commission on Social Determinants of Health. Closing the gap in a generation: health equity through action on the social determinants of health. Geneva: World Health Organization, 2008.

4. Van Weel C, De Maeseneer J, Roberts R. Renewing primary health care: integration of personal and community health care. Lancet 2008; 372: 871-872.

5. Rhyne R, Bogue R, Kukulka G, Fulmer H. Community-oriented primary care: health care for the 21st century. Washington, DC: American Association for Public Health, 1998.

6. Starfield B, Shi L, Macinko J. Contribution of primary care to health systems and health. Milbank Q 2005; 83(3): 457-502.

7. Shi L, Starfield B, Kennedy BP, Kawachi I. Income inequality, primary care, and health indicators. J Fam Pract 1999; 48(4): 275-284.

8. Shi L, Macinko J, Starfield B, et al. The relationship between primary care, income inequality, and mortality in the United States, 1980-1995. J Am Board Fam Pract 2003; 16(5): 412-422.

9. Shi L, Starfield B, Politzer R, Regan J. Primary care, self-rated health, and reductions in social disparities in health. Health Serv Res 2002; 37(3): 529-550.

10. Politzer R.M, Yoon J, Shi L, et al. Inequality in America: the contribution of health centers in reducing and eliminating disparities in access to care. Med Care Res Rev 2001; 58(2): 234-248.

11. Leggetter S, Chaturvedi N, Fuller JH, Edmonds ME. Ethnicity and risk of diabetes-related lower extremity amputation: a populationbased, case-control study of African Caribbeans and Europeans in the United Kingdom. Arch Intern Med 2002; 162(1): 73-78.

12. Ryes H, Perez-Cuevas R, Salmeron J, et al. Infant mortality due to acute respiratory infections: the influence of primary care processes. Health Policy Plan 1997; 12(3): 214-223.

13. Perry H, Robison N, Chavez D, et al. The census-based, impactoriented approach: its effectiveness in promoting child health in Bolivia. Health Policy Plan 1998; 13(2): 140-151.

14. Shekhar S, Rani M. Worlds apart: Why are Kerala and Uttar Pradesh so different in their human developments? World Bank Report. Washington, DC: World Bank, 2003.

15. Gwatkin DR. The need for equity-oriented health sector reforms. Int J Epidemiol 2001; 30(4): 720-723.

16. Jone G, Steketee RW, Black RE, et al. How many child deaths can we prevent this year? Lancet 2003; 362(9377): 65-71.

17. Starfield B. Is primary care essential? Lancet 1994; 344(8930): $1129-1133$

18. Weinick RM, Krauss NA. Racial/ethnic differences in children's access to care. Am J Public Health 2000; 90(11): 1771-1774.

19. Lieu TA, Newacheck PW, McManus MA. Race, ethnicity and access to ambulatory care among US adolescents. Am J Public Health 1993; 83(7): 960-965.

20. De Maeseneer J. Family medicine: an exploration. PhD thesis. Ghent: Ghent University, 1989.
21. Starfield B, Shi L. Policy relevant determinants of health: an international perspective. Health Policy 2002; 60(3): 201-218.

22. Vuori $H$. The role of the schools of public health in the development of primary health care. Health Policy 1985; 4(3): 221-230.

23. Unger JP, De Paepe P, Ghilbert P, et al. Disintegrated care: the Achilles heel of international health policies in low and middleincome countries. Int J Integr Care 2006; 6: e14.

24. Olivera-Cruz V, Kurowski C, Mills A. Delivery of priority health services: searching for synergies within the vertical versus horizontal debate. J Int Dev 2003; 15(1): 67-86.

25. Ageel AR, Amin MA. Integration of schistosomiasis-control activities into the primary-health-care system in the Gizan region, Saudi Arabia. Ann Trop Med Parasitol 1997; 91(8): 907-915.

26. Moerman F, Lengeler C, Chimumbwa J, et al. The contribution of health-care services to a sound and sustainable malaria-control policy. Lancet Infect Dis 2003; 3(2): 99-102.

27. Wilkinson D. Tuberculosis and health sector reform: experiences of integrating tuberculosis services into the district health system in rural South Africa. Int J Tuberc Lung Dis 1999; 3(10): 938-943.

28. Ooms G, Van Damme W, Baker B, et al. The 'diagonal' approach to Global Fund financing: a cure for the broader malaise of health systems? Global Health 2008; 4: 6.

29. Unger JP, De Paepe P, Green A. A code of best practice for disease control programmes to avoid damaging health care services in developing countries. Int J Health Plann Manage 2003; 18 Suppl 1: S27-S39.

30. Brown A. Integrating vertical health programmes into sector wide approaches-experiences and lessons. Swiss Agency for Development and Cooperation. London: Institute for Health Sector Development, 2001.

31. De Maeseneer J, van Weel C, Egilman D, et al. Strengthening primary care: addressing the disparity between vertical and horizontal investment. Br J Gen Pract 2008; 58(546): 3-4.

32. De Maeseneer J, van Weel C, Egilman D, et al. Funding for primary health care in developing countries: money from disease specific projects could be used to strengthen primary care. BMJ 2008; 336(7643): 518-519.

33. Martinez J. Implementing a sector wide approach in health: the case of Mozambique. London: HLSP Institute, 2006. http://www.hlspinstitute.org/files/project/100615/Mozambique_S WAP.pdf (accessed 30 Sep 2009).

34. Pust R, Dahlman B, Khwa-Otsyula B, et al. Partnerships creating postgraduate family medicine in Kenya. Fam Med 2006; 38(9): 661-666.

35. De Maeseneer J, Flinkenflögel M. Primafamed network for training family physicians in Sub-Saharan Africa, an Edulink-ACP-EU project. http://www.primafamed.ugent.be/primafamededulink/index.html (accessed 30 Sep 2009).

36. World Health Organization. Primary health care: now more than ever. Geneva: World Health Organization, 2008.

37. Mash R, Downing R, Moosa S, De Maeseneer J. Exploring the key principles of Family Medicine in sub-Saharan Africa: international Delphi consensus process. S A Fam Pract 2008; 50(3): 60-65.

38. Tollman S, Pick W. Roots, shoots, but too little fruit: assessing the contribution of COPC in South Africa. Am J Public Health 2002; 92(11): $1725-1728$

39. Hugo J, Allan L. Doctors for tomorrow. Family medicine in South Africa. Grahamstown: NISC South Africa, 2008. 